This is a self-archived - parallel published version of this article in the publication archive of the University of Vaasa. It might differ from the original.

\title{
Cloud platforms for remote monitoring system : a comparative case study
}

Author(s): Hao, Yuiuge; Helo, Petri; Gunasekaran, Angappa

Title: $\quad$ Cloud platforms for remote monitoring system : a comparative case study

Year: $\quad 2019$

Version: Accepted manuscript

Copyright (C)2019 Taylor \& Francis. This is an Accepted Manuscript of an article published by Taylor \& Francis in Production planning and control on 04 Dec 2019, available online: http://www.tandfonline.com/10.1080/o9537287.2019.1631459.

\section{Please cite the original version:}

Hao, Y., Helo, P., \& Gunasekaran, A., (2020). Cloud platforms for remote monitoring system : a comparative case study. Production planning and control 31(2-3), 186-202. https://doi.org/10.1080/o9537287.2019.1631459 


\section{Cloud platforms for remote monitoring system: A comparative case study}

\section{Yuqiuge Hao*}

School of Technology and Innovations, University of Vaasa, Vaasa, Finland

yuqiuge.hao@uva.fi

Petri Helo

School of Technology and Innovations, University of Vaasa, Vaasa, Finland

petri.helo@uva.fi

Angappa Gunasekaran ${ }^{\mathrm{b}}$

School of Business and Public Administration, California State University, Bakersfield, U.S.A

agunasekaran@csub.edu

*Corresponding author 


\title{
Cloud platforms for remote monitoring system: A comparative case study
}

\author{
Abstract: \\ Currently, industrial companies are increasingly introducing services to extend their \\ tangible products. Remote monitoring solutions are one of the most implemented \\ services by machine builders to manage their relationship with customers and also \\ improve their business performance in the digital manufacturing era. However, the \\ conventional method of remote monitoring cannot fulfil distributed business \\ environments. Therefore, new solutions are needed to enable remote connection in \\ manufacturing. By reviewing recent literature and proposing new features for software \\ which can be used for remote service and operations, this research paper introduces a \\ remote monitoring system connecting into a central cloud-based system with edge \\ computing network architecture, namely Cloud-based Remote Monitoring (CloudRM). \\ This proposed CloudRM also has been implemented in two different case companies \\ for analysis and evaluation from a value proposition and technical implementation \\ point of view. It shows significant improvement of production management and \\ measurement by using CloudRM.
}

Keywords: Cloud solution, Edge computing, Service-based business solutions, Remote monitoring. 


\section{INTRODUCTION}

Recently, many machine builders, also known as OEMs (original equipment manufacturers), benefit from technological advances by offering multiple services to extend original tangible products provided to customers (Brax \& Jonsson, 2009; Bloss, 2009). The servitization of manufacturing enables companies to meet customized requirements, improve quality, achieve greater profits, and increase customer satisfaction (Chiu \& Chiou, 2016; Peillon, Pellegrin \& Burlat, 2015). For instance, remote monitoring technology is widely implemented to quick detect, analyse and correct unexpected equipment failures in isolated and distributed locations. It enables manufacturers to transform from selling products toward selling performance, operations, and maintenance of products as a bundled product-servicesystem.

With the combination of technology push and business needs, many types of remote monitoring platforms have mushroomed to optimize business operation and processes. Cloud computing, as one of the advanced technological concepts, has a great range of advantages and important aspects, such as scalability, multi-tenancy, configurability and fault-tolerance parallel computing, amongst others. These benefits are reasons for researchers and practitioners to consider applying cloud solutions to remote monitoring. Additionally, IoT (Internet of things) has been extensively applied to improve the performance of core activities in manufacturing industry. The development of IoT increases the availability and visibility of field data by IoT-enabled smart assets; therefore, many real-time manufacturing information platforms have been developed for product and service lifecycle management (Kong et al., 2015; Chiu \& Chiou, 2016). The combination of cloud and IoT is particularly essential for the remote capabilities which can be used for support operation management tasks in manufacturing industry. However, there has been insufficient research work on cloud-based remote monitoring solutions to solve machine builders' problems.

In this research, our purpose is to develop a generic and integrated platform for OEM to enable remote access and monitoring of machinery. The intentions of the platform are extending the scope of industrial services, enabling operation optimization and performance 
measurement. This platform is designed to collect configurable data by IoT technologies and process the data both on site and centrally by cloud-based solutions. Multiple discrete data sources from different aspects are combined together, such as data from fleet, operators and machines. The control engineers and back office personnel have real-time visibility into the installed base and asset utilization; hence the operation and performance can be improved. However, it is problematic when the devices on site collect huge quantities of data. This will yield significant performance overhead on handling the data (Wu et al., 2017). Toro, Correa and Ferreira (2018) point out that in order to stream the sensor data to the cloud platform, it requires different industrial protocols and several configurations with the local network. Therefore, edge computing can support the cloud with more efficient processing capability (Shi \& Dustdar, 2016). Hence, the cloud with edge computing network architecture is applied on this platform in order to achieve our research goal.

The goal of this research is to understand the technological and business impacts of cloudbased remote monitoring solutions and associated management principals. In order to accommodate the research goal, we arrive at a research question: 'How can cloud-based remote monitoring support the operations at different business levels in the manufacturing industry?'

In this paper, a new method of implementing a generic cloud-based remote monitoring (CloudRM) system is presented to monitor machine status and information through Internetrelated communication technology. The paper is based on qualitative case studies. Two machine builder companies, for the food processing and mobile power generator sectors, are introduced respectively. Both of these case companies implemented CloudRM solutions to manage their distributed assets and to enable remotely access and control on cloud-based architecture. They achieved their business goals and strategies, and also improved their performance by introducing CloudRM.

By presenting the results from these two case studies, this research aims to further understanding of cloud-based remote monitoring. The specific benefits of this CloudRM include: 
- CloudRM enables distance access to multiple sites and extend the scope of manufacturing services.

- Edge computing is adopted at customers' sites in this solution to overcome the shortages of conventional cloud solutions in data handling and processing. The rest of this paper is structured as follows. Section 2 presents a literature review for remote monitoring and its applications by machine builders. Section 3 explains the methodology used in this particular research. Section 4 provides the conceptual framework. A cloud based remote monitoring system for machine builders is also proposed in this section. Section 5 presents a comparative analysis of two case companies. Section 6 closes the research by a reference to challenges and future perspectives.

\section{LITERATURE REVIEW}

\subsection{Remote Monitoring}

Recently, remote monitoring is always provided with the physical product as a service in different industries to improve the product quality and customer experience (Noh \& Hong, 2011). The application of a remote monitoring system extends broadly into the prevailing trends, such as the marine industry (Kuschel \& Ljungberg, 2005), environmental research (Kotenev et al., 2010; Yang et al., 2018), automation production (Noh \& Hong, 2011), health care (Van der Velde et al., 2012; Vacher et al., 2006), manufacturing industry (Wang et al., 2009; Wang et al., 2011; Jonsson, 2006), the mining industry (Carter, 2011), etc.

A remote monitoring system consists of two Internet-connected systems: a local system (various hardware) and remote system (software). The hardware refers to the integration of sensor and wireless technology to collect real-time data about the products' status (i.e. health, location, changes over time and field performance). Typically, sensors are embedded in the products and automatically collect data. On the other hand, software means data management related activities, such as data acquisition, data transmission and data processing algorithms technologies (Jonsson et al., 2008; Noh \&Hong, 2011).

At the early stage of remote monitoring, the data collection mainly relies on manual 
activities, such as barcode scanning or on-site downloading, and then it is brought back for analysis (Guo et al., 2015). This results in incomplete and lagged data. Because business requirements have trended toward constant surveillance and rapid detection of changes, continuous data collection is now critical. Remote monitoring is entering a new era with the development of wireless sensing devices (Grubic, 2012) and other Internet technologies (Wang, Peter \& Lee, 2007). When the data is accessed in real-time, it adequately achieves continuous remote monitoring and provides early warning information to enable proactive operations. The users can concentrate on data analysis rather than data collection. This is crucial to decision-makers so that they can find trends based on previous data and respond appropriately before an actual error happens.

In manufacturing industry, a remote monitoring system changes the way people work, and it provides more possibilities and a comprehensive way into the working environment to fulfil manufacturing servitization. Grubic (2012) investigated many concrete examples by intensive literature review and claimed that most remote monitoring applications are for service providers, which implies the capacity of remote monitoring systems for supporting service offers and innovating service delivery.

On the trend of moving toward globalization in the manufacturing industry and the development of information and communication technology (ICT) and various mobile devices, monitoring the state of production facilities is essential for maintaining consistency, reliability and productivity in full automation systems and working environment (Wang, Peter \& Lee, 2007). A remote monitoring system can automatically monitor machine performance, detect the occurrence of abnormality, predict risks, prevent breakdowns and diagnose problems, then send notification to the supervising personnel or service technicians located at a remote location. Therefore, it enables continuous decision-making over the status changes (Jonsson, 2006).

Companies adopt remote monitoring systems for various purpose, for example security (Takeda et al., 2010), quality control (Takeda et al., 2010), reducing the risks of servitization 
(Grubic \& Peppard, 2016), or avoiding on-site work. The benefits of the remote monitoring system can be considered from both the point of view of manufacturers and customers (Grubic, 2012).

(1) The advantages of remote monitoring for manufacturers can be discussed both internally and externally. It can improve employees' performance, increase the availability of their products, improving insight into the machines' production, and reduce the cost and response time. Externally, manufacturers get direct access to the operational data from customers by using IoT and maintain a close relationship with them (Grubic \& Peppard, 2016; Rymaszewska, Helo \& Gunasekaran, 2017). This feedback can enable knowledge creation from learning and improve the R\&D (research and development) process.

(2) Customers can request a resolution of errors in a timely manner because the manufacturers have a complete insight into customers' needs and how customers actually use products by using remote monitoring. Customers benefit from the minimized downtime and transfer of risks to the manufacturer's side (Grubic \& Peppard, 2016). Furthermore, customers need to connect and integrate machine data into external systems in order to make intelligent operational decisions.

Although the importance of remote monitoring has been acknowledged, there are still several challenges to be addressed:

- Due to the lack of advanced remote monitoring technology, it is challenging to share and integrate heterogeneous data from distributed locations (Grubic, 2012).

- Due to the lack of standardizations, the collected data is difficult to generate and formalize valuable knowledge to enable operational decisions (Grubic, 2012). Especially there are some tasks that need accurate action to accomplish (machine operation activities) in a complicated, distributed manufacturing environment (Wang, Peter \& Lee, 2007). 


\subsection{Machine builders}

OEMs are also referred to as machine builders and sometimes as systems integrators. There are two types of machine builders: some have the capabilities to develop in-house systems, and others have to use industry standard or team up with third party providers to provide customer equipment.

As competition has increased in many fields due to globalization, machine builders cannot rely on pure physical products, but need comprehensive solutions with supplemental services. Manufacturing servitization is considered as one of the critical developments to improve the industry's competitiveness in the market. A well-known example of this is Rolls Royce's 'power-by-the-hour' strategy used in the business of aero engine service, namely engine health management (EHM) to support their total care offering for gas turbines on aircraft (Grubic \& Peppard, 2016 ). Today, similar concepts are used in other domains. For example, Wätsilä provides gas and diesel power plants by using long-term contracts and charging customers according to electricity produced. Siemens made significant investment in realtime monitoring for rail to accelerate their digital services for predictive maintenance.

IoT is a driving force for traditional manufacturers to enhance their business offering from physical products to information and services and thus change the competition (Porter \& Heppelman 2014). It enables an enterprise information system to understand the event, status and actual condition in the physical world. The IoT consists of interrelated sensors, processors and communication hardware to collect, send and act on data acquired from surrounding environments (Grubic, 2012; Yang et al., 2018). In order to enable the remote monitoring system, a certain level of situational awareness of products, processes and customers is required. Many smart technologies are used, such as RFID (radio frequency identification) (Zhou, Ling \& Peng, 2007; Wang et al., 2011), sound/speech recognition system (Vacher et al., 2006), vibration sensor (Noh \& Hong, 2011), wireless sensor network (WSN) (Gui et al., 2011), ZigBee (Cheng et al., 2012), image processing and motion detector (Takeda et al., 2010), amongst others. GE (General Electric), one of several high-profile 
companies, uses IoT capabilities in some of its products for remote monitoring purposes, including in aircraft engines to optimize fuel use (Michel, 2014).

IoT is based on a convergence of multiple automation and data communication technologies that, in turn, enable OEMs to incorporate more intricate levels of intelligence into their machines, extending connectivity deeper and deeper into component tiers. Many OEMs provide customer service by utilizing remote monitoring centres. The latest iteration in this ongoing advancement of remote connectivity now makes it possible for OEMs and system owners to access data from machine sensors - the same devices that helped make automated machinery possible. For instance, IoT facilitates remote monitoring at the PLC (programmable logic controller) level which has become quite common across a broad range of industrial automation machines. OEMs can instantly access the machines and perform setup, diagnostic and process optimization tasks.

Grubic and Peppard (2016) summarize the service offering by remote monitoring in three parts: design-engineering-manufacturing, operational control, and maintenance and logistics. Figure 1 shows possible service products driven by remote monitoring that may be offered to support (1) the management of a company, (2) operations and maintenance (O\&M) of equipment and (3) site support.

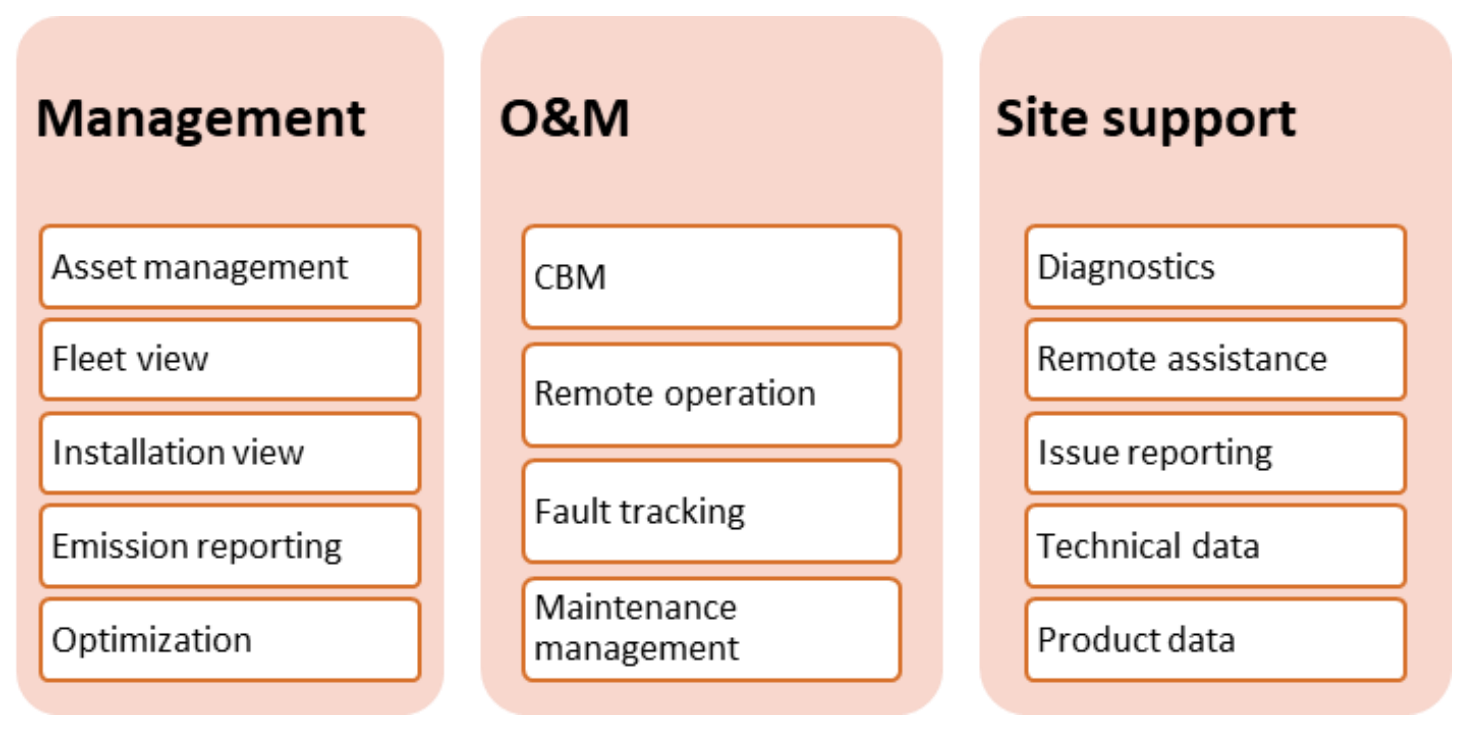

Figure 1. A set of applications built by OEMs for improving customer business. 
- Management of a company: machine builders can always gain business benefits and profits from remote monitoring capabilities. There is much evidence to show that companies have a more comprehensive insight into the performance of their products in use and the behaviours of customers by collecting data about their installed base (Grubic \& Peppard, 2016). By monitoring all the raw materials and equipment, it is easy to achieve resources and operational optimization and planning. This enables asset and fleet management services (Grubic, 2012; Carter, 2011). The availability of fleet and tracking of assets at operational level management are a crucial factor for a company's effectiveness. Emission is another critical performance parameter that needs to be reported (Mills, 2011; Noh \& Hong, 2011). For many OEMs, the driving forces for optimization of resources and operations are the possibility to improve fuel efficiency and reduce reported emissions.

- Operations and maintenance $(\mathrm{O} \& \mathrm{M})$ : The remote monitoring process improves manufacturers' efficiency and effectiveness in their O\&M. It is possible to take actions such as repairing and maintenance before actual problems happen. This can prevent losses, disruptions and environmental, safety, and other hazards harming the customer's business (Grubic, 2012). Moreover, there is a need to change focus from capital expenses toward operational expenses. An example of justifying the purchase of an energy efficient electrical motor could be that $90 \%$ of the life-cycle cost is electricity cost, and only $10 \%$ is the purchase cost of the equipment. Centralized monitoring and diagnosis can improve the equipment performance, decrease maintenance costs and lower outage rates (Douglas, 2004). Condition-based maintenance (CBM) systems can provide an early warning of unexpected equipment status, and allow maintenance to be proactive, rather than reactive, and in this way lower life-cycle costs (Douglas, 2004; Mills, 2011).

- Site support: Some OEM monitoring systems analyse data from a wide variety of machines to enhance the customers' machine performance (Carter, 2011). In order to improve the coordination of maintenance and other related activities, it is critical to 
combine maintenance operation and product data. Therefore, data about the installed base collected through remote monitoring technology makes the performance of products and customer behaviour transparent to both the manufacturer and customer. Therefore, the manufacturer can gain better understanding of the customers and insight into their business as well as their products in the field (Grubic, 2012).

\subsection{Toward cloud-based systems}

The scope of current literature deals with the technical implications of using remote monitoring systems to support manufacturing service-oriented business models. Owing to the rapid growth of Internet technology and web-based technology, the remote monitoring system is no long limited to SCADA (supervisory control \& data acquisition technology), but elevates to a new level. Data transfer requirements can be fulfilled by the use of the Internet as a communications approach for the remote maintenance of even sophisticated manufacturing equipment (Biehl, Prater \& Mclntyre, 2004). Traditional remote monitoring processing methods cannot satisfy the requirement of dynamic monitoring (Zou, 2017).

In the contemporary technological society, cloud computing has become a new trend of Internet applications. Cloud computing can provide an effective and large-scale data processing and computing execution over the Internet (Zou, 2017; Yang et al., 2018). It brings potential benefits and new business models for various industries and applications. Industry 4.0 is a project promoted by the German government, and it defines the next generation of manufacturing where cloud and other related advanced technologies, i.e., IoT and cyber-physical systems (CPS) are used to provide automation for operations and production, as a smart factory (Rymaszewska, Helo \& Gunasekaran, 2017). Advanced technologies enable the ability to interact with manufacturing services over the Internet (Toro, Correa \& Ferreira, 2018). This concept covers a wide range of applications from product design, production monitoring and control, to final logistics (Zheng et al., 2018). Xu (2012) proposes the 'cloud manufacturing' concept. He emphasizes the importance of partially handing over some operational activities to cloud services, such as remote 
monitoring and managing the manufacturing resources.

Cloud-based remote monitoring services enable the constant collection and analysis of data to support the control and management of manufacturing processes (Toro, Correa \& Ferreira, 2018). Ren et al. (2017) also posit that by applying industrial IoT in a cloud manufacturing collaboration environment, it will allow effective remote monitoring, operation and resource scheduling. Based on the information and data obtained from the IoT, smart or cloud manufacturing applications return management and control commands back to IoT devices or machines/equipment on site. It is the trend that cloud-enabled solutions and IoT become the preferred technologies for machine monitoring systems. There are several reasons for moving towards the cloud:

(1) Internal integration: Sensors and data acquisition with monitoring capabilities at the machine shop floor level need to be connected to enterprise level applications. Using a cloud based solution makes the business and operation infrastructure flexible and scalable.

(2) Distributed manufacturing: Remote monitoring is crucial in distributed manufacturing across multiple plants, including the concepts of virtual factories and networks. Cloud technology provides an approach to handle distributed manufacturing to maintain high productivity and flexibility (Guo et al., 2015). In a cloud infrastructure, a multitenancy system architecture is always employed. Specifically, different cloud consumers use the applications as different instances of a central implemented core application, and the instances are organized in a single logical environment on the cloud (Mell \& Grance 2009; Dillon, Wu \& Chang, 2010).

(3) Large volume of data and equipment: In order to enable real-time or near real-time remote monitoring, potentially useful data about machine states, alarm statuses, operator feedback, etc. are recorded on a continuous basis. Especially for companies with multiple plant facilities, itis very challenging to process and store a vast amount of automatically generated data at such high rates. Therefore, a cloud-based solution 
can be adopted to provide scalability and flexibility during data processing and maintain the system performance (Cheng et al., 2012; Yan et al., 2018).

Several recent types of research have proposed remote industrial monitoring systems using a cloud infrastructure. Ren et al. (2017) demonstrate a cloud-based application to perform remote monitoring of tasks-in-progress on a machine; Yan et al. (2018) propose a cloudbased production system to support massive remote sensing data storage and processing; and Hossain and Muhammad (2016) present a cloud-based health monitoring system to connect IoT devices and sensors, people, and applications. Michel (2014) points out the possibility of the combination of alert monitoring service (AMS) with cloud-based maintenance software to ensure secure connection and troubleshooting of problem issues with customers.

According to previous research, cloud-based infrastructure can collect industrial data from local sensors and then transfer data from the plant floor to cloud to support data processing tasks. Moreover, web-based GUIs (graphical user interface) are implemented for users to interact with the systems.

Although there are many advantages in moving to the cloud, there are still many concerns and bottlenecks in cloud-based manufacturing regarding remote monitoring services (Tao et al., 2011a; Huang et al., 2013; Rauschecker \& Stohr, 2012; Wu et al., 2017), such as network, standards and security issues.

- Network bottleneck: Typically, raw data from the data producer and requests from data consumers transfer through the network in the cloud infrastructure. However, it requires a lot of bandwidth and sufficient computational capacity when IoT is implemented in the structure, because large data volumes are collected and parallel algorithms for analysing data are involved. Therefore, it is crucial to find an efficient architecture and offload some computing tasks to the network edge.

- Lack of standards: In many legacy machines, it is not possible to monitor equipment conditions due to lack of equipped sensing technologies. Even in many modern 
manufacturing machines with various sensors for remote monitoring and control, there are several protocols and standards for the communication between equipment and devices. However, there are no effective standards when the communication is cloud based. It is important to standardize the communication procedure.

- Security risks: Companies' privacy and security are always the primary concern when moving towards any cloud-based applications, especially using cloud computing with the IoT. It is challenging to open up the network of the shop floor and allow message transfer and data sharing by cloud based remote monitoring. Many companies hesitate to allow access through their firewall and in the meantime have to put their sensitive and valuable data onto an external server.

Wu et al. (2017) point out that although HPC (high performance computing) is one of the solutions to the challenges in implementing remote monitoring systems in cloud computing, it is very expensive to build the infrastructure on factory floors and very inefficient in terms of machine learning and algorithms. Therefore, edge computing is introduced as an extension of cloud-based solutions to address the aforementioned limitations.

Edge computing is a new paradigm involving leveraging cloud computing infrastructure, which enables the computing and storage to be placed near data sources at the network edge (Shi \& Dustdar, 2016). To be more precise, intensive computation tasks, such as training large datasets and visualizing data analytics, are performed in edge computing at locations where large volumes of data are collected and stored. This can address the shortage of location-awareness in cloud computing (Wu et al., 2017; Luan et al., 2015).

Based on the key features, the main purpose of edge computing is to provide services to the IoT environment. When the amount of raw data gradually increases to be enormous in various IoT applications, conventional cloud computing is not efficient enough to handle all the data. Therefore, it is more efficient to process the data at the edge of the network rather than transmit it to the cloud (Shi \& Dustdar, 2016). 
Adopting edge computing can reduce response times, improve the data processing, conserve network pressure and reduce energy consumption significantly (Shi \& Dustdar, 2016; Jain \& Singhal, 2016). However, issues such as system reliability, security, privacy and energyconstrained edge devices should be taken into account.

In summary, the literature review in this section presented related work based on previous research. However, literature on designing and implementing cloud based applications is scarce and the problem of how to realize the connection between the site and remote centre remains to be solved. The implementation of cloud-based remote monitoring should be carefully considered from different aspects. In this research, cloud computing, IoT and edge computing are integrated to address the lack of research and the practical gap.

\section{METHODOLOGY}

\subsection{Research approach}

The methodology of this paper is an applied exploratory/descriptive case study approach. This method is widely used in social sciences, business and planning (Yin, 2013) and increasingly in software engineering (Runeson \& Höst , 2009) to generate deeper understanding of the phenomenon.

This approach allows exploring the need - seeking insights and generating ideas, describing typical user situations and improving certain aspects (Robson, 2002). The reason for using this case approach is that enterprise software development involves multidisciplinary perspectives (Runeson \& Hös , 2009). A case study approach is prevalent in relatively new research areas, such as the cloud computing research field. For instance, Erdem et al. (2016) conducted a case study to define a conceptual framework for cloud-based virtual laboratories. Kong et al. (2015) proposed a cloud-enabled solution for adaptive planning and control based on a case of an auction logistics centre. Moreover, case studies are well suited to the context of remote management - the phenomenon is studied in a natural setting and the focus is on a topical issue (Benbasat, Goldstein \& Mead, 1987). 
In this study, a three-step research approach is applied to develop a technical framework for cloud-based remote monitoring service:

- Conceptual framework: The conceptual framework is proposed. It presents an overview of cloud-based remote control systems. It starts from an investigation of business processes and generic requirements from machinery builders. It consists of core business processes and extended remote control services.

- Case studies: Empirical research demonstrates how to deploy the proposed CloudRM infrastructure and services in two case companies for remote monitoring purposes. In order to increase understanding of the case studies, interviews were conducted to collect primary data.

- Evaluation: This step includes a system evaluation and a future investigation. It ensures competitive advantage for the machine builders in varying future situations.

\subsection{Case scenario description}

In this research, empirical data were collected from two case companies with a view to justifying the research questions and displaying how the proposed generic cloud-based remote monitoring solution could be implemented for the benefit of the case companies. Both case companies were studied by their similarity and differences. The background of development of the case companies is similar: both are seeking technological support to create service product for the installed base of products. However, they had different practical industrial problems to be solved.

A set of common characteristics are also found in these two companies, making the research results more trustworthy and reliable:

(1) The companies offer customized solutions to their customers to solve particular problems.

(2) The companies provide field services for their customers, such as assembly, installation and maintenance. 
(3) The companies have been investigating possibilities for improving their after-sales services through remote monitoring solutions for diagnostic and maintenance management purposes.

The proposed CloudRM architecture has been applied in the case companies. For confidential reasons, the fictional names Company A and Company B are used throughout this reporting. Both studied companies can be described as technological leaders in their fields. Case Company A is focusing on sites with fixed locations, and Company B is working mainly with mobile assets. Both companies are located and operate in Finland and serve customers in Scandinavia. Table 1 illustrates the companies' industries, business goals and industrial problems, respectively.

Table 1. Overview of case study companies.

\begin{tabular}{|c|c|c|}
\hline & Company A & Company B \\
\hline Industry & $\begin{array}{l}\text { Machine builder for food processing } \\
\text { machines }\end{array}$ & $\begin{array}{l}\text { Machine builder for mobile power } \\
\text { generators }\end{array}$ \\
\hline $\begin{array}{l}\text { Main } \\
\text { products }\end{array}$ & $\begin{array}{l}\text { Processing of root vegetables and } \\
\text { salads (e.g. potato peeling machines) }\end{array}$ & $\begin{array}{l}\text { Portable power generators for the } \\
\text { construction industry }\end{array}$ \\
\hline $\begin{array}{l}\text { Business } \\
\text { goal }\end{array}$ & $\begin{array}{l}\text { 1) Work closely and collaborate with } \\
\text { customers to better understand } \\
\text { customer business needs in detail } \\
\text { 2) Provide customer optimized food } \\
\text { processing solutions and make } \\
\text { adjustments instantly when } \\
\text { needed }\end{array}$ & $\begin{array}{l}\text { 1) Analyse the usage of various machines } \\
\text { from the customers' perspective, and } \\
\text { propose useful machine plans to } \\
\text { enhance their customers' machine } \\
\text { performance } \\
\text { 2) Eliminate unnecessary visits to remote } \\
\text { sites to improve customer services } \\
\text { while reducing the costs }\end{array}$ \\
\hline $\begin{array}{l}\text { Industrial } \\
\text { Problems }\end{array}$ & $\begin{array}{l}\text { 1) Difficult to achieve real-time } \\
\text { monitoring and remote control } \\
\text { over the machines } \\
\text { 2) A lot of bandwidth is required for } \\
\text { uploading videos in order to fulfil } \\
\text { the monitoring functionality }\end{array}$ & $\begin{array}{l}\text { 1) Security issues with data } \\
\text { communication remain in its business. } \\
\text { 2) Lack of visibility of power } \\
\text { consumption and power output to } \\
\text { achieve optimal execution. }\end{array}$ \\
\hline
\end{tabular}

In order to understand the implementation of a cloud-based remote monitoring solution for 
machine builders, semi-structured interviews were conducted in both cases, and also the companies' documents were collected as secondary data. The respondents were not only internal stakeholders, but also external stakeholders selected from the case companies, such as project managers, technical experts and external customers, etc. In total, three group interviews were conducted across the two case companies during 2016. The interviews were performed at the company site and started with a tour of the working environment. Each interview was stimulated by the researchers as a group discussion, and all the interviews were analysed and compared across case-specific background afterwards. The questions were structured from four aspects:

- the current business situation of their companies,

- the development of product and service offerings,

- potential customers' requirements and solutions of remote monitoring services, and

- the important trends of relevant services.

Following this data collection and analysis structure enabled comparisons of similarities and differences. The analysis results were reported to each company for verification. However, the detailed questions were adapted according to different companies and different respondents. Although the interviews were not recorded due to confidential reasons, cross validations were performed among all researchers after each interview. Following this process generated a broad view of the case scenario.

\subsection{Analysis procedures}

Both case companies wanted to offer industrial services as a core competitive strength to their customers by implementing a cloud-based remote monitoring platform. This strategy decision led towards a technical development of the solutions. For our research purpose, there were two rounds of analysis in the analysis procedures. Firstly, primary analysis was performed: the general information and company background were evaluated and the researchers also had chance to experience the working environment during the tour of the site. Secondly, case-specific analysis was performed. In Company A, the researchers wrote write- 
ups from groupings of interviews based on interviewee roles. In Company B, the researchers made company-level write-ups. These were then compared by looking at similarities and differences, and by distinguishing categories of findings. After the analysis procedure, both companies received preliminary versions of their research reports with oral presentations.

\section{CONCEPTUAL FRAMEWORK OF CloudRM FOR MACHINE BUILDERS}

\subsection{Cloud-based remote monitoring architecture}

This research proposes and develops a remote monitoring system concept for machine builders (OEMs) to manage their customers' assets. The system can remotely collect realtime data from different equipment made by different manufacturers (machine builders), and used by different customers. This data collection realizes remote monitoring and fault diagnosis. Compared with conventional remote monitoring systems, this new concept has the characteristics and infrastructure to exist in a cloud-based solution, not only using an agentbased communication channel. Moreover, in order to deal with the huge amount of data generated from equipment at customer sites, edge computing is adopted to alleviate the network pressure and overcome the data challenges. Firstly, with the benefit of multi-tenancy architecture, this system sustains multi-user operations in a cloud structure. Secondly, edge computing enables the data analysis and data collection to be performed on the edge of network, closer to the source of the data. Instead of sending every generated data to the cloud server for processing, the equipment and IoT devices connect through a local gateway. This allows faster analytics and reduces network pressure. The system has different solutions and private data centres for different machine builders. However, all solutions share the core concept. Machine builders can connect different customers into this system by configuration controls with very low additional cost. It is very easy to expand the scope of remote monitoring services.

Figure 2 illustrates a high-level overview architecture of the cloud-based remote monitoring system. It is achieved by a two-layer-network structure, namely a local layer and cloud layer. 
The machine builder company consists of one or more customer companies, and each customer company has several working sites for physical manufacturing activities. Each site has a number of production lines and equipment in use. Each site collects local information by IoT nodes and sends it over the local area network (LAN) to an edge gateway, at the local layer. The edge gateway is an entry point between data source and the cloud servers. Then the data is sent to centralized cloud servers by wide area network (WAN), at the cloud layer. By using this structure, the data collection can be tailored according to specific requirements, and also the data processing power can be distributed on both the local network and cloud network.

In this research, the industrial assets not only reside in a fixed-location; they can also be mobile devices, such as a truck or other service vehicle. For the customers, several cloudbased remote monitoring applications are provided by using the centralized server. The remote monitoring applications allow users to view plant data generated by their systems from a remote location.

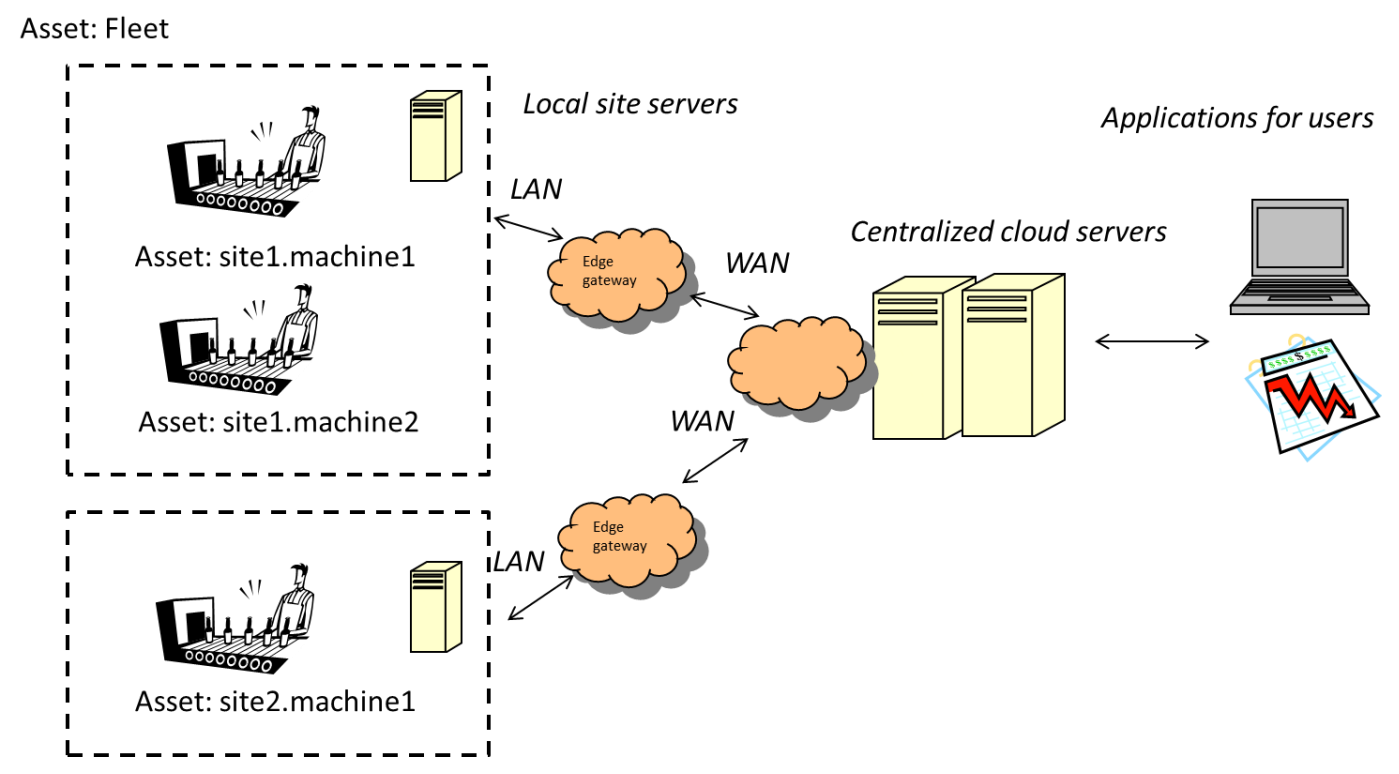

Figure 2. Cloud-based system architecture for remote management of fleets and assets.

As emphasized in Figure 2, the machine builder company is the owner of CloudRM. The end users are not only the customer companies' machine operators and fleet managers, but also 
other partners in the ecosystem, such as external service providers and suppliers. This system can enable both the machine builder company and its customer companies to make better decisions on fleet management and process monitoring, and this system increases the visibility of the whole operations process and the value chain.

However, due to the large amount of data and high requirement of the time scale, the data collection affects the efficiency of database operations. Regarding different management levels, the data can be divided into three levels, namely machine builder company level, customers' company level, and shop floor levels, as shown in Figure 3. Besides these three levels, industrial IoT nodes reside on the edge of the network as edge devices. Each level of data must be tracked and monitored in a timely and accurate manner. Various users can access the same data and collaborate: customer, manufacturer and even external vendors.

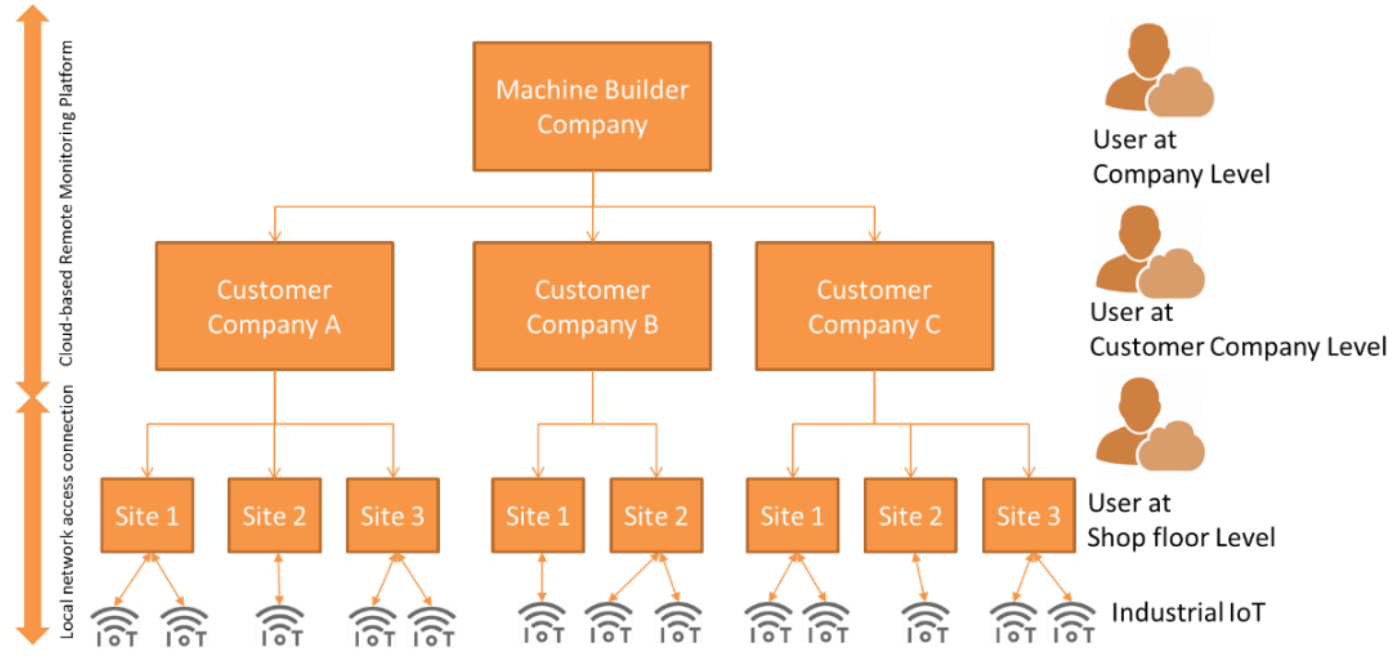

Figure 3. Data management hierarchy and internet working model for multi-tenant system.

At the edge, the IoT applications not only produce data and send it back to the cloud, but they also process the data and perform computing tasks. For instance, in reality, although the manufacturer is at the top level and can access all data, the detailed production information has not been taken into consideration in the high-level production management activities because raw data about production records are insufficient to fulfil the requirements of monitoring and support the decision making. It is important to extract valuable parameters 
from the raw data based on the users' different business purposes according to specific monitoring requirements. Therefore, redundant IoT data can be reduced based on the CloudRM platform and its relevant manufacturing requirements and policies, and the errors can be pre-processed at the edge network before being delivered to the cloud platform. Moreover, some responses can return to the IoT devices based on decision making policies without sending a request back to the cloud. This can improve the frontline supervision on the shop floor by improving the operations and response time.

Figure 4 presents the functional architecture of the CloudRM to illustrate an example of both the cloud server and the local server. The left side of the figure shows three logical parts in the cloud server.

- The local human-machine interface (HMI) layer handles interaction and communication between remote support and local operator or maintenance personnel. The graphical presentation and local authorizations are inherited at this layer.

- At the application layer, different applications can be loaded as modules to support site-level functionality.

- The system core runs the most central parts of the processes.

The right side of Figure 4 presents the remote management local site software components. Real-time/Near-real-time data acquisition and processing requires an advanced data processing mechanism. Therefore, the OCP (Open Compute Project) server and local data storage are implemented as a data centre at the local site. The rule engine processes aggregation, alert and event-based data manipulation actions and stores data to the local database or sends processed data to the cloud server. The communication module handles external communication with the central cloud. 


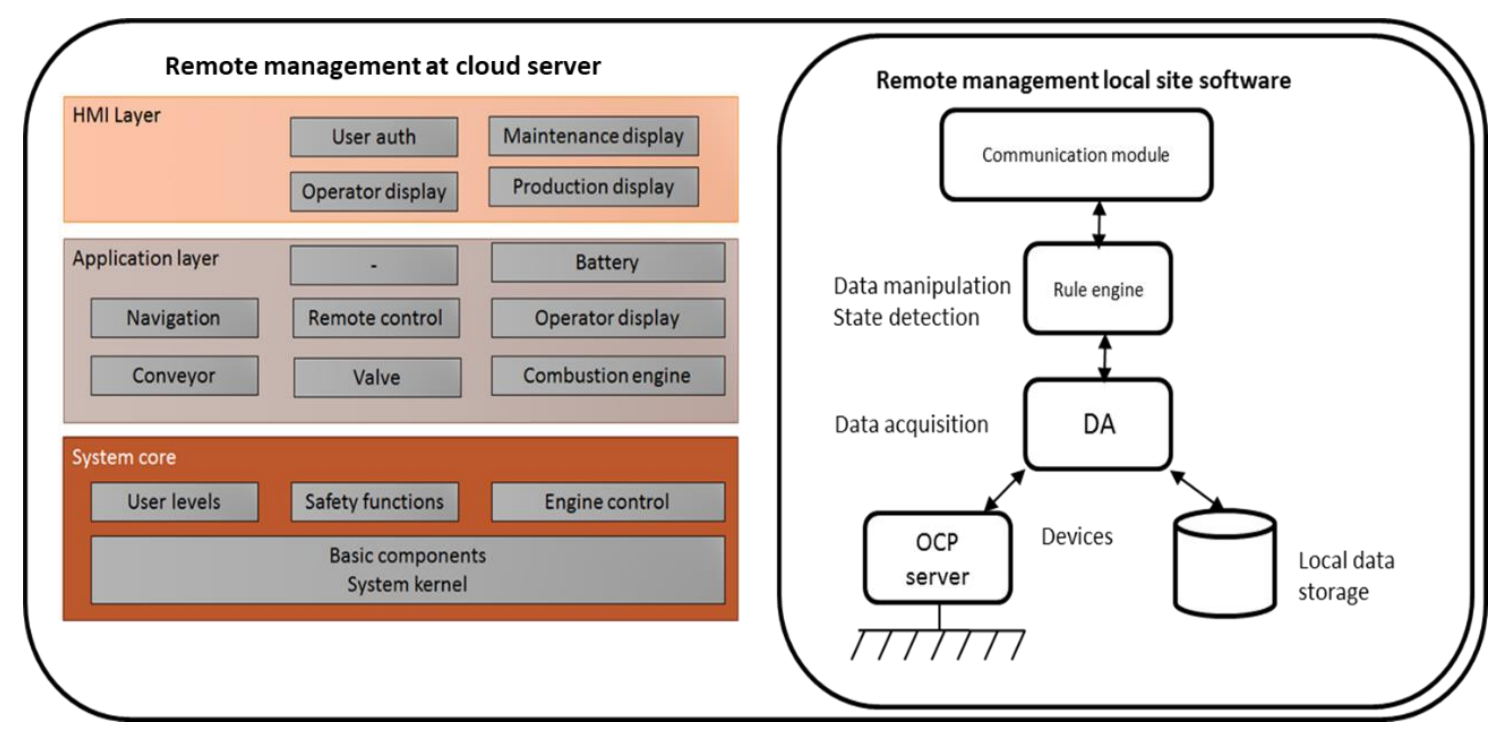

Figure 4. Functional architecture of the CloudRM.

In this architecture, there are two types of connections: the connection between IoT at the local site and edge server, and the connection between edge server and cloud server. A cloud server manages the entire system, including all the applications and contents. At the edge, selective localized applications are provisioned and synchronized with the cloud.

- Connection between IoT at the local site and edge server: Production data from the production frontline is collected by the IoT environment. IoT enables improved manufacturing automation activities and remote monitoring by tracking objects and supervising the work flow. The information includes products, machine states, processing time, operations, etc. PLC (programmable logic controller) is used to collect data from the site and transfer the data to the local host sever (edge server) via the communication network.

- Connection between edge server and cloud server: The local site level system communicates with cloud servers by using a https-based communication protocol tunnelled in a VPN (virtual private network). Both synchronous and asynchronous data communication may take place (as shown in the left side of Figure 5). As a layering principle, guidelines such as OSA-CBM (Open System Architecture for Condition Based Maintenance) or ISO 13374: Machine Condition Assessment Data 
Processing \& Information Flow Blocks (as shown in the left side of Figure 5) are used as a communication framework to provide a functional platform flexible enough to suit a broad range of applications.

Communication modes

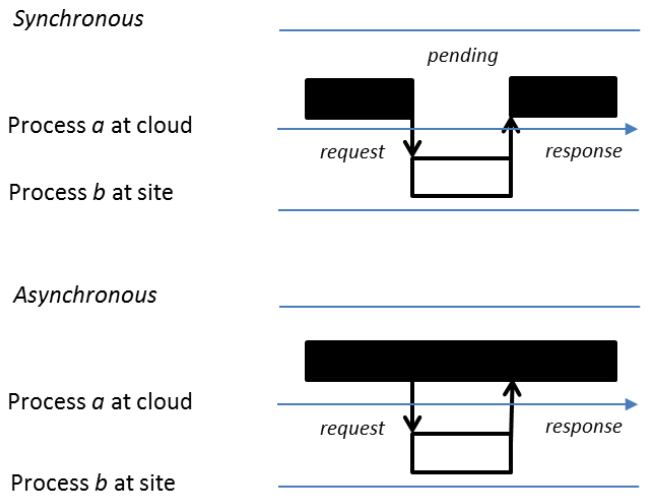

Processes communicated between site and portal

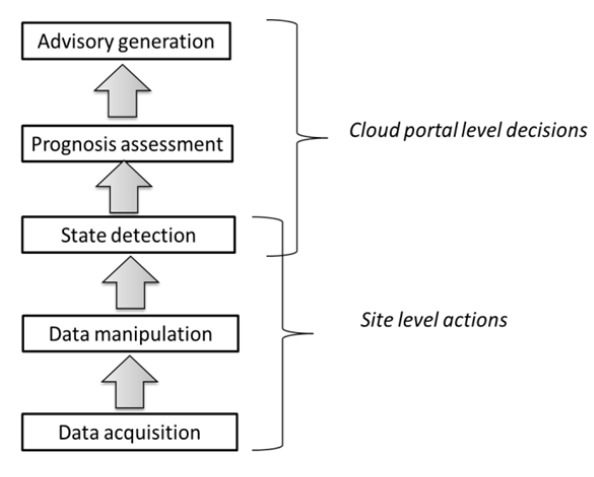

Figure 5. Example of layered processing between site core and centralized cloud portal.

\subsection{Local layer: Edge at customer site and data communication}

It is very important to set up reliable and efficient edge computing at the customer site to ensure that the edge and cloud architecture can support the local asset management. The important feature of the local site level system is to provide access to sensors, and monitor and record sensor and operations information. The low-level data are processed and stored on the most detailed level for a given period. However, data from multiple edge devices locally should be combined centrally to provide a holistic view. Therefore, the edge structure needs to fulfil two requirements at the same time: ensure real-time decision making at the edge of network, and also provide historical analysis for centralized business improvement.

Machines at the sites communicate with the bus service of the cloud server. An enterprise bus service handles authentication and message queues for requests and responses. Aggregate production data from different locations is fed into centralized data processing and storage components. A generic asset structure ontology aims at flexibility of the storage model and the possibility to enhance the system with new applications. 


\subsection{Cloud layer: Centralized cloud servers}

Centralized cloud servers provide a web portal user interface on each machine and fleet level reports. These are the tools used for expert analysis and maintenance planning. Different applications can be installed as separate components. Typically, centralized cloud servers containing asset information are connected to external data sources. The cloud infrastructure supports the communication among machine manufacturer, customer companies and end-users. They consume the data gathered by the cloud service from the IoT devices. Customer relationship management data and other environmental data such as weather information may be used for data mashup and advanced analyses. Figure 6 shows an example of a web portal displaying sensor data as time series.

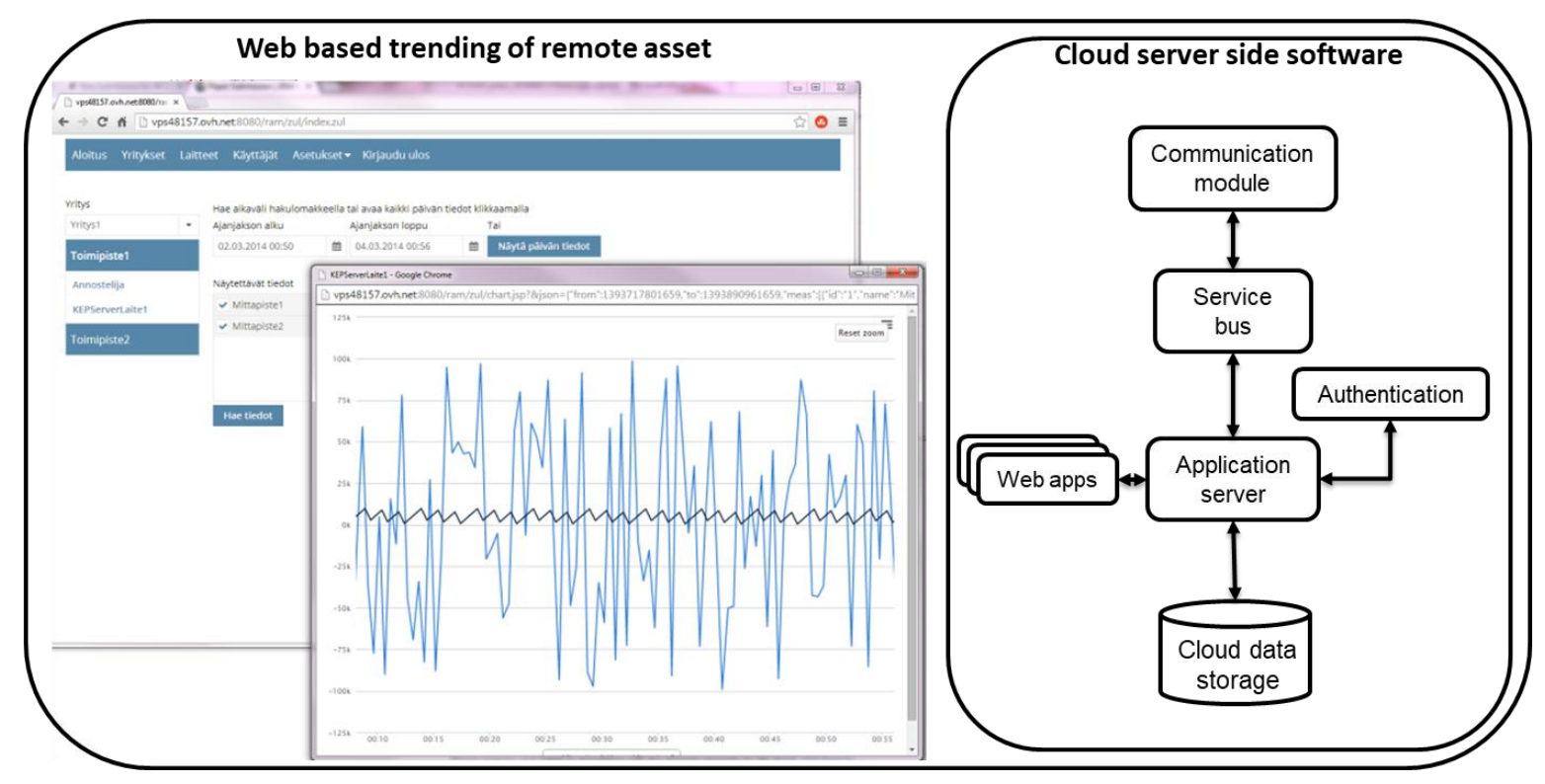

Figure 6. Web-based trending of remote asset at the cloud server and key components of cloud central.

In order to deal with the security and other challenges possibly encountered in cloud-based architecture, there are primarily three deployment models of cloud centralized servers, and the decision is made based on use case and business requirements: 
- Public cloud: It is owned by a third-party IT service provider, and generally is suitable for SMEs (small and medium sized enterprises) to extend their IT capabilities and resources.

- Private cloud: It is managed within a machine manufacturer to provide an integrated IT structure for distributed resources.

- Hybrid cloud: It is a combination of both public and private cloud that integrates the standardized IT resources on the public cloud and maintains unique resources on the private cloud.

In the traditional cloud deployment model, the community cloud is also an option for service providers. It enables information exchange internally through specific application standards. However, it is not applicable in the cloud-based remote monitoring system, because customers are not interacting with others but only with the machine builder company (service provider). The customers are not sharing the services and data with others in an internal community cloud.

Based on the generic architecture proposed in this research, two prototypes have been developed to support real-time, scalable, and plug-and-play data collection for both legacy and modern manufacturing machines. These prototypes enable online remote manufacturing process monitoring, diagnosis and prognosis, as well as proactive maintenance scheduling.

\section{CASE STUDY ANALYSIS}

\subsection{Food processing machinery}

Company $\mathrm{A}$ is a machine builder specializing in automated food handling equipment and systems for root vegetable and salad processing technologies. It is located in Finland and provides high-performance food processing equipment to small and medium sized food manufacturing companies in the Nordic area. Company A is responsible for designing, manufacturing, installing and supporting the food processing equipment, with the goal of improving the productivity of customers' companies. Besides equipment, company A also 
manufactures complete lines to customers.

Company A provides real-time, centralized, cloud-based remote monitoring of customers' manufacturing. There are two purposes: first, monitoring the food processing machines can adjust the process accordingly to reduce the waste and increase productivity. For instance, the entire peeling process is monitored, and certain KPIs (key performance index) are set up for evaluation (i.e. peel percentage, raw material load speed, surface defects), and to ensure the peeling quality. This remote monitoring can increase the yield, lower the peeling loss, and speed up the cycle time.

Second, this continuous monitoring centre can address a maintenance problem more easily and fix it faster. This significantly reduces unexpected events and also eliminates delays in the customer's production schedule. The monitoring can solve two types of maintenance, namely error-based and schedule-based maintenance. Error-based maintenance (reactive maintenance) refers to the situation when abnormal changes during machine executions are detected and monitored, and then maintenance services can be provided to the site immediately. Schedule-based maintenance (proactive maintenance) means periodic maintenance to check the status of a machine. The maintenance personnel can obtain data about a machine's status or error report generated by remote monitoring. Therefore, the process of maintenance service will be shortened and unlikely to delay the original production process. As a result, this remote monitoring can improve customer service and increase customer satisfaction.

Figure 7 illustrates a high-level overview of Company A that leverages the cloud-based remote monitoring system (CloudRM). It comprises one or more customers' facilities, each having a number of food processing equipment items in use. The equipment includes different kinds of functionalities for food preparation: peeling and profiling, followed by processing. The food processing line is a sequential process: for example, sorting, peeling, vegetable washing, soil and stone separation, cutting and slicing, profiling, dosing, weighing and packing. In order to solve the particular industrial problem, central operation monitoring 
is designed for each site through an edge of the network. The operating conditions (i.e. machines, operators and response rates, etc.) are real-time monitored to generate early observation of issues and abnormalities. A huge amount of data is collected daily based on various sensors, including peel percentage, raw material load speed and surface defects. The data are also analysed locally and the some decisions are made locally on the site. Therefore, the maintenance personnel can obtain data about machines status or error report generated by remote monitoring in near real-time. In this approach, they do not need to wait for decisionmaking from the cloud, and only summarized data is sent to it.

In this case company, the proposed CloudRM provides tools for recording food processing and machine status, and enables remote monitoring and performance analysis. Once implemented, a CloudRM provides real-time information about the raw materials, machine conditions and associated processes. These metrics will be used for determining overall equipment effectiveness (OEE).

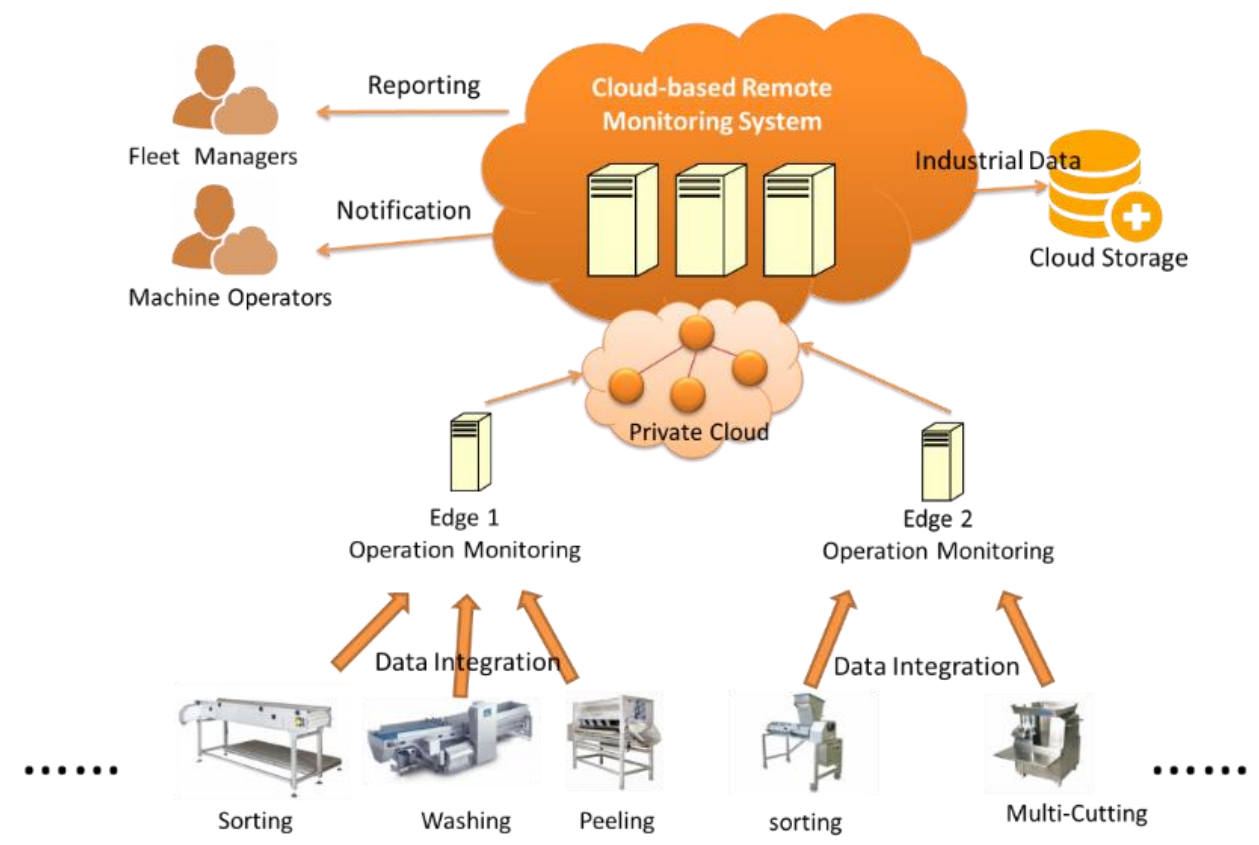

Figure 7. Remote Monitoring System Integration by Cloud for Company A.

- Users: Company A's maintenance supervisors, the customer company's site managers and the machine operators are the primary users. The cloud infrastructure provides a set of web-based tools that allow users to retrieve data from the cloud. Users can 
receive notifications and reporting when an error happens; they can also get a visualized analysis result shown on their devices, such as mobile phones, larger screen monitors or on-site screens.

- Data Integration: Serialized site data from equipment and IoT are periodically collected and integrated into the plant facility server at the network edge, and then the data are packed and sent to the cloud platform through a cloud network connection by using a data service agent. However, the data do not need to be sent back to the cloud immediately after they are produced. The edge system can only report important data to a central cloud.

- Private cloud: This cloud-based infrastructure can facilitate automation data and related information gathering, transmitting, and remote monitoring. Unlike in the conventional system, the acquired data can be intelligently organized and sorted based on selected criteria in cloud-based infrastructure. The criteria can be customized and peer-defined by users at each edge on site. In this configuration, the cloud platform is a private cloud operated internally by Company A. Each private cloud can comprise a set of servers hosting the cloud services and residing on a corporate network protected by a firewall.

- Cloud storage: With the respect to the main characteristic of industrial automation, i.e. vast data continually generated daily by an industrial enterprise, cloud storage is chosen as a scalable solution. Cloud storage can be easily scaled to adapt the large amount of data into the working environment. Moreover, many industrial companies are organized with multiple geographically distributed facilities. Therefore, the automation data from different locations can be migrated to the cloud for the purposes of central aggregation, analysis and reporting.

\subsection{Mobile power generators}

Company B is a mobile machinery solutions provider. The company specializes in management solutions for mobile power generators. Customized trailers are designed to 
transport the mobile power generator sets to different places where reliable power is required. These working environments are often located in remote areas and always need massive equipment, but it is difficult and expensive to implement the local power supply. For instance, temporary power is required in the early stages of construction to support the heavy equipment. Therefore, a mobile power generator is required to support this equipment. All trailers are equipped with an engine governor, fuel tank, electricity storage, cooling system, etc.

The power consumption and running time of machines may vary throughout the day as well as between different working days. Because the generators are normally designed to meet the largest intermittent loads, when small loads are connected to the generators, it is possibly wasting fuel due to the oversize of the generators. Such power generators need consistent monitoring to ensure that they are working correctly, and also to ensure that they are providing accurate and regular amounts of power to support all other equipment, not wasting any fuel, and not risking a shortage of fuel. Therefore, it is critical to monitor the power production in certain working sites, and also monitor the power generation in a certain working environment. The production cost of electricity produced can be compared between units, sites and alternative sources where available. The purpose of the remote monitoring is also to ensure Company B provides customized and optimized solutions to their customers.

Figure 8 demonstrates the overview concept of CloudRM for Company B. Each working site is defined as a mobile factory, which contains mobile power generators and other types of machinery and equipment. The data about power consumption and power generation are collected separately, but simultaneously. This data must be analysed and reported at edge of the network in the remote facilities, in real time, so its outcomes are immediately actionable for personnel at the site. Mobile machines are connected by using data transmission technology developed for telephone networks or satellite connection because of remote locations outside cellular network coverage. Besides the action on site, data at the edge node also need to be subsequently synchronized with the cloud in the background. Therefore, 
customers can always check the status of the power generator related to their work sites anywhere, such as the machine's history, status, and performance. In the same way, centralized web servers are accessible from all around the world.

When working outfield and having all the machines at remote locations, robust, reliable, and secure network connection are critical. Therefore, a security mechanism is designed in this solution. The connections from remote locations to CloudRM via VPN and network security protocol are deployed within the private cloud, which can serve the local internal needs of each mobile factory. Figure 8 shows the CloudRM implemented in Company B.

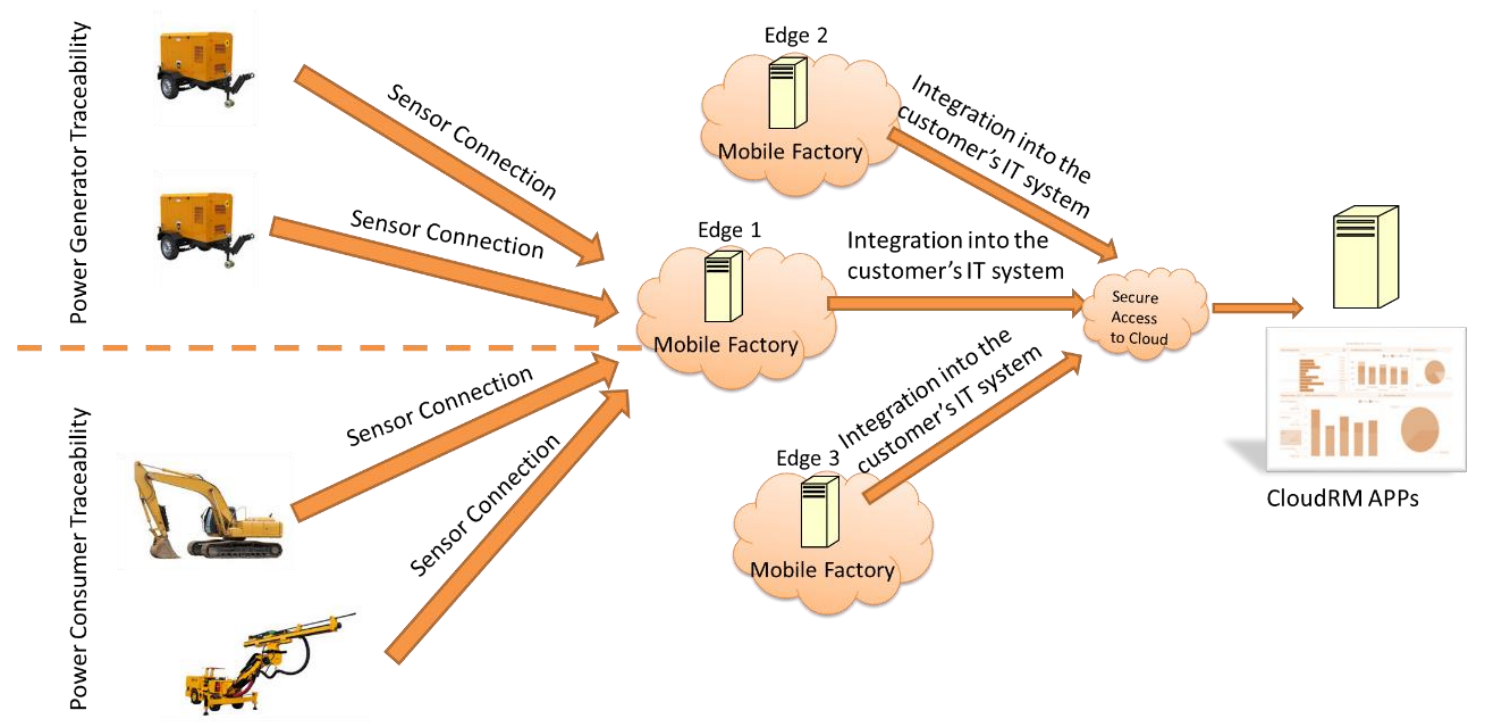

Figure 8. Remote Monitoring System Integration by Cloud for Company B

Cloud-based servers and Internet connections have good availability, and thus reliable business processes can be built around these. Different edges at each mobile factory are compared across site and time. This CloudRM features an integrated web-based interface, and customers can access specific mobile factory information via a PC or mobile devices, regardless of operating system or browser type. The customer can set the desired intervals to receive data automatically from the mobile factory. The information includes current operating status, maintenance schedule, historical information, etc. CloudRM provides complete mobile factory monitoring, remote diagnosis, data storage and display. 
Edge devices, i.e. modern technologies of sensors, computers and telecommunication have enabled the possibility of having frequent connection to an installed base. These mobile machines used in a particular mobile factory include full-scale embedded computers and advanced sensors. The sensor in the mobile machinery collects data, and this process is shown in Figure 9.

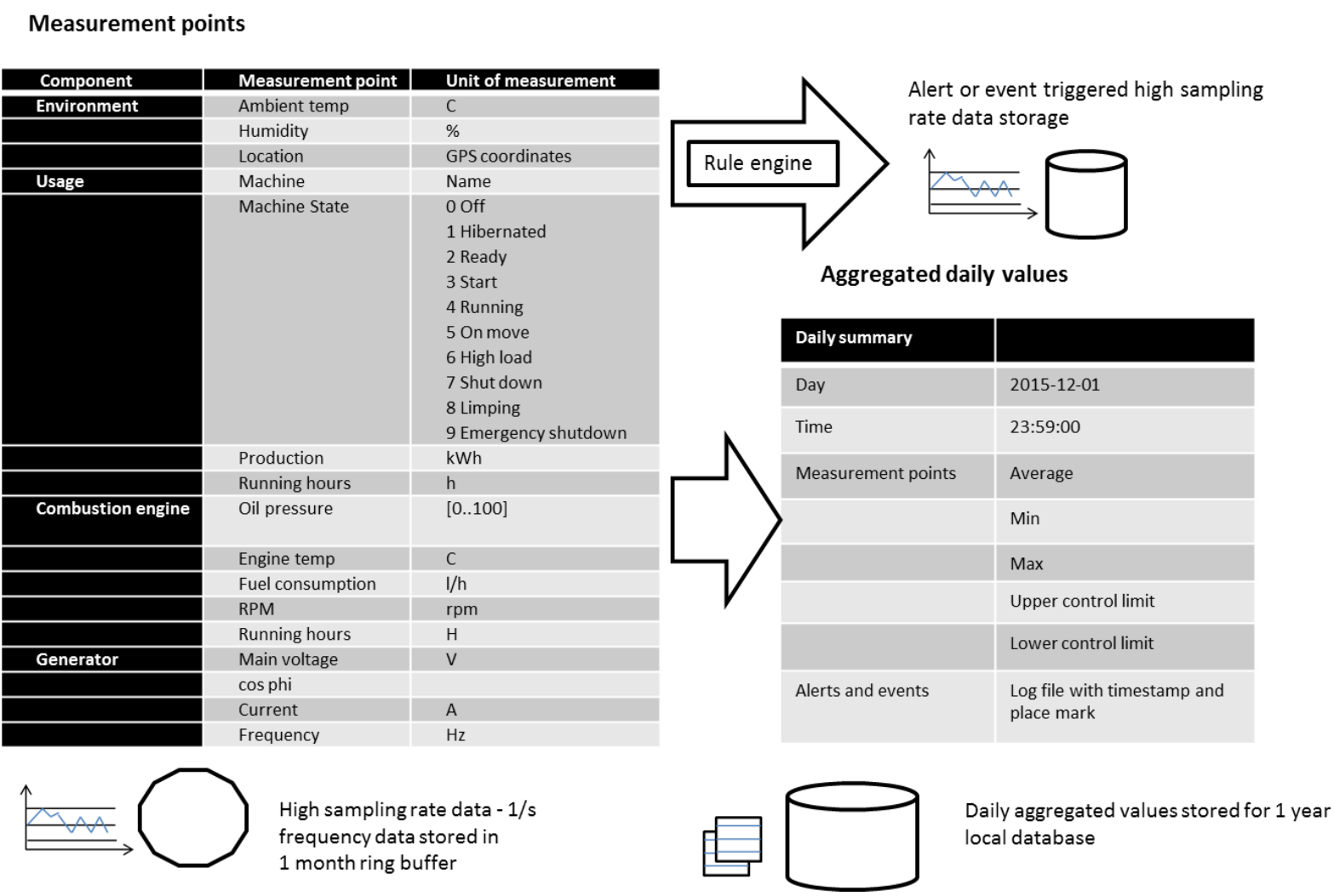

Figure 9. Customers calculate the power consumption price based on the following KPIs.

All the industrial plant data in a cloud storage can be accessed by a web-based dashboard.

KPIs in the reporting dashboards enable all users to assess business performance in real time. In order to evaluate whether the power generation and power consumption are effective or producing the expected results, both company B and its customers can track a KPI over a period. Information such as machine running hours and fuel consumption are displayed on the remote dashboard. Users can flexibly compare different data sets based on their interests and needs. In order to visualize the location of the geographically distributed engines, a map or a satellite image is used in the dashboard. 


\subsection{Results and discussions}

This research sought to find how cloud-based remote management is being used to support OEMs' business and services. By analysis of two case companies and their CloudRM implementation, several results were found. From the enterprise information system perspective, cloud-based remote management systems in both food production and power generation cases have certain similarities. Remote monitoring opens windows to the actual use of machinery. Real operating profiles and condition data can bring value for both operators as well for the machine builders. The presented technical architecture has been operationalized in both cases. For both cases a small focused set of business KPIs have been pre-defined, and the whole technical structure has been derived from the objectives. High level operational metrics should guide service products, including advisory, maintenance planning, and overall asset utilization improvements.

Table 2 summarizes the two case studies in structuring the flow from business requirements to actual implementation. This top-down structure guides the answering of design questions such as: What parameters need to be monitored? How should data aggregation be processed? What types of reports are required for end-users? Generic platform components can be used as long high-level objectives and KPIs are linked to operational parameters. Cloud infrastructure systems have requirements for security and capacity, but typically specific features are not necessarily needed. Data aggregation and eviction policies should be designed to support the operations and maintenance cycles. A good architecture should support an approach where time series data handling tasks can be divided between site and central cloud, depending on data transfer cost and capacities. Therefore, edge computing is the solution for handling data on site and offloading certain computing tasks and improving response time.

Table 2. Case result summary.

\begin{tabular}{|l|c|c|}
\hline & $\begin{array}{c}\text { Case A- Food processing } \\
\text { machinery }\end{array}$ & Case B- Mobile power generators \\
\hline Business KPI & $\bullet$ Life-cycle OPEX [EUR/y] & $\bullet$ Cost of electrical energy produced \\
\hline
\end{tabular}




\begin{tabular}{|c|c|c|}
\hline & $\begin{array}{l}\text { - Tons of goods produces [tns/day] } \\
\text { - Quality of product processed } \\
\text { [FPY \%] }\end{array}$ & $\begin{array}{l}\text { [EUR/kWh] } \\
\text { • Fuel consumption }[1 / \text { hour }]\end{array}$ \\
\hline Business model & $\begin{array}{l}\text { - Optimized supply of } \\
\text { consumables } \\
\text { - Leased equipment to customer }\end{array}$ & $\begin{array}{l}\text { - Reduced energy cost at mobile } \\
\text { sites }\end{array}$ \\
\hline Operations change & $\begin{array}{l}\text { - Condition monitoring } \\
\text { - Remote advisory service } \\
\text { - Supply of consumables }\end{array}$ & $\begin{array}{l}\text { - Operations monitoring } \\
\text { - Fuel consumption tracking }\end{array}$ \\
\hline Cloud service & $\begin{array}{l}\text { - Centralized and run by the } \\
\text { equipment manufacturer }\end{array}$ & $\begin{array}{l}\text { - Centralized by the operating } \\
\text { company }\end{array}$ \\
\hline Communication & $\begin{array}{l}\text { - Continuous fixed Internet } \\
\text { connection } \\
\text { - VPN network }\end{array}$ & $\begin{array}{l}\text { - Mobile Internet for mobile fleet of } \\
\text { equipment } \\
\text { - Mobile VPN network }\end{array}$ \\
\hline Site system & $\begin{array}{l}\text { - Local embedded PC with process } \\
\text { data storage, communicating } \\
\text { PLC based control and sensor } \\
\text { values read from equipment }\end{array}$ & $\begin{array}{l}\text { - PLC based system reading values } \\
\text { into memory and flushing to } \\
\text { centralized OPC server }\end{array}$ \\
\hline
\end{tabular}

In summary, this CloudRM can address the customer's need to monitor and optimize the performance of assets in real time. Using CloudRM solves three primary typical issues in conventional remote monitoring systems:

1) When the large quantity of data generated by industrial facilities operating on a 24-hour basis, it can be collected in near real-time. The remote monitoring solution and the devices do not have to share a common network with the location where data are collected. The raw data are processed at the edge of the network, then the response time can be reduced, and the performance improved. This can help personnel at the site to make real time decisions.

2) When dealing with multiple facilities at geographically distributed locations, the data available on mobile machines or remote facilities do not need to reside on the same local network as the remote monitoring solution: they are located at different edge nodes. However, the data will be finalized and processed on the centralized cloud in order to support business 
decisions.

3) In conventional cloud structure, the floor shop data must upload to a remote cloud server, and then the customer retrieves the data from a long-distance link from the cloud. By using the edge computing model, the data and application services are put as close as possible to the customers' sites. The customers can access the data at the local connections inside the shop floor.

Of course, it is important to think how cloud computing and edge computing complement each other. Cloud computing is still an important processing paradigm and a more generalpurpose platform. It is useful in applications that are not as sensitive to a time- out response, where the device does not need processing power itself or big data applications. It serves to increase the efficiency of everyday tasks and provides an approach to massive data handling.

On the other hand, edge computing has benefits for applications where the device has data processing capabilities and needs to quickly process data in response to manufacturing parameters that may or may not be within limits. That said, inventory control information is not likely to utilize edge computing. Processing these transactions at the edge of the network would result in a distributed, unsafe and uncontrollable disarray of data.

Security and privacy are additional concerns. On the one hand, edge computing better protects data because processing occurs closer to the source than in cloud computing. However, supporting security and privacy is more difficult in edge computing due to network topology, the many inexpensive personal mobile devices in the system, and sensor unreliability.

\section{CONCLUSIONS}

Remote monitoring is acknowledged and widely used as a key application of IoT, though there are some limitations and challenges. The first and the most obvious problem is data related issues, such as the lack of standardization to support data sharing, data integration, and data transmitting among different manufacturers (Grubic, 2012; Wang, Peter 
\& Lee, 2007). Secondly, different remote monitoring systems have different architectures. For instance, there are several remote systems in a production line for complicated machinery. But without a common interface, each of the systems considers itself as a main portal and all other components are forgotten. So it is important to consider the compatibility of different systems and different data sources. In addition, quality control is an important factor to ensure data utility.

The Internet has become an important component of remote systems, and it has provided all the abilities of monitoring and diagnosing. However, when service technicians' devices are disconnected from the internet, it is very risky when the technicians cannot check the machine status in real-time. It is not convenient for engineers or managers who are only interested in whether the machine works well. In some instances, engineers need to check the machine status regularly even when the systems do not send alarm messages automatically. Therefore, internet connection is very critical (Wang, Peter \& Lee, 2007).

Implementing remote monitoring operations within a cloud environment is a solution for the current globalized manufacturing industry. However, it is very challenging. Companies transforming towards service and operations built on top of remote management systems should consider the following:

(1) linking objectives with operational key performance indicators (KPIs) to support the business model and operational changes implemented,

(2) planning how achieved benefits are shared between solution providers and end-users,

(3) permanent agreements and fair rules between parties about benefits (asset owners, machine builders),

(4) data ownership questions agreed (operators, vendors, maintenance),

(5) technical architecture to support restricted access and local authorization.

Moreover, in cloud scenarios, different types of clouds should be considered to cope with different interoperations in the remote monitoring system. It is natural that the transforming 
and adaptation will gradually progress. The security issue is still a highly sensitive topic in surveillance. Cloud security is the prior pre-condition for the success of a cloud-based solution.

In this study, a cloud-based remote monitoring system (CloudRM) is introduced to solve the distributed surveillance challenges for machine builder companies and other practical problems. On-site monitoring always has physical limitations and boundaries. A conventional remote monitoring solution limited in efficiency due to complex IoT applications, different machines and various parameters. CloudRM provides an alternative to a conventional solution with the help of lower cost of technical infrastructure, more flexibility and more functionality, which involves a combination of edge computing and cloud architecture. Technically, this structure can reach more robust data handling capabilities than traditional cloud architecture through edge network. From the business perspective, machine builder companies can manage their customers' operations and monitor the customers' machines to provide better services for them. Additionally, machine builder companies can also maintain their relationship with other partners and suppliers. The proposed solution has been applied to two case companies and the feasibilities tested in a broader implementation scenario.

Additionally, both case companies have considered designing a security mechanism in their cloud infrastructure to provide safety assurance. Otherwise, there are non-functional issues, such as the privacy of the operator personnel and ethical regulations. Although they are not addressed in this study, they should be treated seriously and not be neglected when designing any remote monitoring system.

Besides the cloud architecture, edge computing technology is becoming an option for smart manufacturing with IoT implementations. In some cases, the manufactories have many sensors, robotics, and automated machines on their manufacturing floors, so they need extra analytics servers that are used on site for computing and analytics. For the manufactories, real-time response on the spot is business critical; therefore, hybrid deployment is preferred. 
There are still plenty of research opportunities left to be explored. In the future, it will be worthwhile building integrated mobile apps to allow users to get immediate alarms for multiple sensors and to monitor the devices in remote locations.

\section{References}

Benbasat, I., Goldstein, D.K. \& Mead, M. (1987). The case research strategy in studies of information systems. MIS quarterly, 369-386.

Biehl, M., Prater, E., \& McIntyre, J. R. (2004). Remote repair, diagnostics, and maintenance. Communications of the ACM, 47(11), 100-106.

Bloss, R. (2009). Machine builders, system integrators and component suppliers showcase innovations at IMTS in Chicago. Assembly Automation, 29(2), 115-121.

Brax, S. A., \& Jonsson, K. (2009). Developing integrated solution offerings for remote diagnostics: A comparative case study of two manufacturers. International Journal of Operations \& Production Management, 29(5), 539-560.

Cheng, J. Y., Hung, M. H., Lin, S. S., \& Cheng, F. T. (2012). New remote monitoring and control system architectures based on cloud computing. Advanced Materials Research, 579, 312-329.

Chiu, M. C., \& Chiou, J. Y. (2016). Technical service platform planning based on a company's competitive advantage and future market trends: A case study of an IC foundry. Computers \& Industrial Engineering, 99, 503-517.

Dillon, T., Wu, C., \& Chang, E. (2010). Cloud computing: Issues and challenges. In International Conference on Advanced Information Networking and Applications (AINA), 2010 24th IEEE (27-33). IEEE

Douglas, J. (2004). Remote Monitoring. Power Engineering. Mar 2004, 108(3),.24-30

Erdem, M.B., Kiraz, A., Eski, H., Çiftçi, Ö., \& Kubat, C. (2016) A conceptual framework for cloud-based integration of virtual laboratories as a multi-agent system approach. Computers \& Industrial Engineering, 102 (2016) 452-457.

Grubic, T. (2012). Servitization and remote monitoring technology: A literature review and research agenda. Journal of Manufacturing Technology Management, 25(1), 6-6. 
Grubic, T., \& Peppard, J. (2016). Servitized manufacturing firms competing through remote monitoring technology: An exploratory study. Journal of Manufacturing Technology Management, 27(2), 154-184.

Gui, Y., Tao, Z. G., Wang, C. J., \& Xie, X. (2011). Study on remote monitoring system for landslide hazard based on Wireless Sensor Network and its application. Journal of Coal Science and Engineering (China), 17(4), 464-468.

Guo, Z. X., Ngai, E. W. T., Yang, C., \& Liang, X. (2015). An RFID-based intelligent decision support system architecture for production monitoring and scheduling in a distributed manufacturing environment. International Journal of Production Economics, 159, 16-28.

Hossain, M. S., \& Muhammad, G. (2016). Cloud-assisted industrial internet of things (iiot)enabled framework for health monitoring. Computer Networks, 101, 192-202.

Huang, B., Li, C., Yin, C., \& Zhao, X. (2013). Cloud manufacturing service platform for small-and medium-sized enterprises. International Journal of Advanced Manufacturing Technology, 1-12.

Jain, A., \& Singhal, P. (2016). Fog computing: Driving force behind the emergence of edge computing. In International Conference System Modeling \& Advancement in Research Trends (SMART), (294-297). IEEE.

Jonsson, K. (2006). The embedded panopticon: Visibility issues of remote diagnostics surveillance. Scandinavian Journal of Information Systems, 18(2).

Jonsson, K., Westergren, U. H., \& Holmströn, J. (2008). Technologies for value creation: an exploration of remote diagnostics systems in the manufacturing industry. Information Systems Journal, 18(3), 227-245.

Kong, X., Fang, J., Luo, H., \& Huang, G. (2015) Cloud-enabled real-time platform for adaptive planning and control in auction logistics center. Computers \& Industrial Engineering, 84 79-90. 
Kotenev, V. A., Tyurin, D. N., Kablov, E. N., \& Tsivadze, A. Y. (2010). System for remote monitoring of environmental aggressively. Measurement Techniques, 53(9), 10801087.

Kuschel, J., \& Ljungberg, F. (2005). Decentralized remote diagnostics: a study of diagnostics in the marine industry. In People and Computers XVIII-Design for Life (211-226). Springer London.

Luan, T. H., Gao, L., Li, Z., Xiang, Y., Wei, G., \& Sun, L. (2015). Fog computing: Focusing on mobile users at the edge. arXiv preprint arXiv:1502.01815.

Mell, P., \& Grance, T. (2009). The NIST definition of cloud computing. National Institute of Standards and Technology, 53(6), 50.

Michel, R. (2014). 4 ways the Internet of things will reshape manufacturing. Modern Materials Handling. July, 2014. 46-52.

Mills, S. (2011). A new standard for condition monitoring. ME Plant \& Maintenance, May/June 2011. 13-14.

Noh, M. S., \& Hong, D. S. (2011). Implementation of remote monitoring system for prediction of tool wear and failure using ART2. Journal of Central South University of Technology, 18(1), 177-183.

Porter, M. E., \& Heppelmann, J. E. (2014). How smart, connected products are transforming competition. Harvard Business Review, 92(11), 11-64.

Peillon, S., Pellegrin, C., \& Burlat, P. (2015). Exploring the servitization path: A conceptual framework and a case study from the capital goods industry. Production Planning $\&$ Control, 26(14-15), 1264-1277.

Rauschecker, U., \& Stohr, M. (2012). Using manufacturing service descriptions for flexible integration of production facilities to manufacturing clouds. In 2012 18th International ICE Conference on Engineering, Technology and Innovation (ICE), (110). IEEE.

Ren, L., Zhang, L., Wang, L., Tao, F., \& Chai, X. (2017). Cloud manufacturing: key characteristics and applications. International Journal of Computer Integrated 
Manufacturing, 30(6), 501-515. Robson, C. (2002). Real world research. 2nd. Edition. Blackwell Publishing. Malden. Runeson, P. \& Höst, M., 2009. Guidelines for conducting and reporting case study research in software engineering. Empirical Software Engineering, 14(2), 131-164.

Rymaszewska, A., Helo, P., \& Gunasekaran, A. (2017). IoT powered servitization of manufacturing - An exploratory case study. International Journal of Production Economics, 192, 92-105.

Shi, W., \& Dustdar, S. (2016). The promise of edge computing. Computer, 49(5), 78-81.

Takeda, K., Hattori, T., Izumi, T., Kawano, H., \& Masuda, S. (2010). Application of SPRT to an image data sequence for a remote monitoring system. Artificial Life and Robotics, $15(4), 421-424$.

Tao, F., Zhang, L., Venkatesh, V. C., Luo, Y., \& Cheng, Y. (2011). Cloud manufacturing: A computing and service-oriented manufacturing model. Proceedings of the Institution of Mechanical Engineers, Part B: Journal of Engineering Manufacture, 225(10), 1969-1976.

Toro, R., Correa, J. E., \& Ferreira, P. M. (2018). A cloud-monitoring service for manufacturing environments. Procedia Manufacturing, 26, 1330-1339.

Vacher, M., Serignat, J. F., Chaillol, S., Istrate, D., \& Popescu, V. (2006, January). Speech and sound use in a remote monitoring system for health care. In Text, Speech and Dialogue (711-718). Springer Berlin Heidelberg.

Van der Velde, E. T., Foeken, H., Witteman, T. A., van Erven, L., \& Schalij, M. J. (2012). Integration of data from remote monitoring systems and programmers into the hospital electronic health record system based on international standards. Netherlands Heart Journal, 20(2), 66-70.

Wang, B., Cao, Z., Yan, Y., Liu, W., \& Wang, Z. (2011). Fundamental technology for RFIDbased supervisory control of shop floor production system. The International Journal of Advanced Manufacturing Technology, 57(9-12), 1123-1141. 
Wang, W., Peter, W. T., \& Lee, J. (2007). Remote machine maintenance system through Internet and mobile communication. The International Journal of Advanced Manufacturing Technology, 31(7-8), 783-789.

Wang, Y. M., Yin, H. L., Xiao, N. F., \& Jiang, Y. R. (2009). Internet-based remote manipulation and monitoring of an industry robot in advanced manufacturing systems. The International Journal of Advanced Manufacturing Technology, 43(910), 907-913.

Wu, D., Liu, S., Zhang, L., Terpenny, J., Gao, R. X., Kurfess, T., \& Guzzo, J. A. (2017). A fog computing-based framework for process monitoring and prognosis in cybermanufacturing. Journal of Manufacturing Systems, 43, 25-34.

$\mathrm{Xu}, \mathrm{X}$. (2012). From cloud computing to cloud manufacturing. Robotics and computerintegrated manufacturing, 28(1), 75-86.

Yan, R., \& Lu, L. (2007, August). Research of remote real time monitor system for electromechanical equipment based on internet. In IEEE International Conference on Automation and Logistics, 2007 (1999-2003). IEEE.

Yang, C., Chen, S., Den, W., Wang, Y., and Kristiani, E. (2018). Implementation of an intelligent indoor environmental monitoring and management system in cloud. Future Generation Computer Systems, https://doi.org/10.1016/j.future.2018.02.041.

Yin, R. K. (2013). Validity and generalization in future case study evaluations. Evaluation, 19(3), 321-332.Zhou, S., Ling, W., \& Peng, Z. (2007). An RFID-based remote monitoring system for enterprise internal production management. The International Journal of Advanced Manufacturing Technology, 33(7-8), 837-844.

Zheng, P., Sang, Z., Zhong, R. Y., Liu, Y., Liu, C., Mubarok, K., \& Xu, X. (2018). Smart manufacturing systems for Industry 4.0: Conceptual framework, scenarios, and future perspectives. Frontiers of Mechanical Engineering, 1-14.

Zou, Q. (2017, April). Research on cloud computing for disaster monitoring using massive remote sensing data. In 2017 IEEE 2nd International Conference on Cloud Computing and Big Data Analysis (ICCCBDA), (pp. 29-33). IEEE. 